\title{
Por uma história decolonial: a atuação das populações afrodescendentes em ambientes socioculturais de Porto Alegre (1872-1971)
}

\author{
For a decolonial history: \\ the atuation of Afro-descendant populations in socio-cultural environments in Porto \\ Alegre (1872-1971)
}

Arilson dos Santos Gomes

Doutor em História pelo PPGH/PUCRS

Professor da Unilab

Universidade da Integração Internacional da Lusofonia Afro-Brasileira arilsondsg@yahoo.com.br

\begin{abstract}
Resumo: Este artigo tem como objetivo destacar a presença de afrodescendentes em espaços culturais e sociais da cidade de Porto Alegre, capital do estado do Rio Grande do Sul, entre os anos de 1872 e 1971. Esse período, que vai desde a fundação da Sociedade Beneficente Floresta Aurora (1872) até a criação do Grupo Palmares em Porto Alegre (1971), um coletivo que propôs o Dia da Consciência Negra, celebrado em 20 de novembro. Em 2021, essa data, proposta como referência simbólica, completa 50 anos desde sua primeira evocação. Portanto, nesta proposta, questiona-se se os representantes negros presentes nos espaços socioculturais de Porto Alegre resistiram à colonialidade e, em caso afirmativo, quais seriam suas proposições de ação para afirmar sua identidade e sua cultura. Por meio de bibliografia pertinente e de entrevista temática (ALBERTI, 2005) com um dos fundadores do Grupo Palmares, será analisada a atuação de sujeitos afrodescendentes no âmbito sociocultural da cidade.
\end{abstract}

\section{Palavras-chave:} Afrodescendentes; Decolonialidade; Grupo palmares.
Abstract: This article aims to highlight the presence of people of African descent in cultural and social places in the city of Porto Alegre, capital of the state of Rio Grande do Sul between the years 1872 to 1971 . Year of foundation of the Sociedade Beneficente Floresta Aurora (1872) until the creation of the Palmares Group in Porto Alegre (1971), a collective that proposed the Black Awareness Day celebrated on November 20. Date proposed as a symbolic reference and that, in 2021, completes the 50th anniversary since its first evocation. Therefore, in the proposal, it is questioned whether the black representatives present in the socio-cultural spaces of Porto Alegre resisted coloniality and, if so, what would be their actions propositions to affirm their identity and their culture. Through pertinent bibliography and thematic interview (ALBERTI, 2005), with one of the founders the Palmares Group, the atuation of Afrodescendant subjects will be examined in socio- cultural the city.

Keywords: Afro-descendants; Decoloniality; Palmares group. 


\section{Considerações iniciais}

A trajetória histórica das populações afrodescendentes, no Brasil, e especificamente na cidade de Porto Alegre, capital do Estado do Rio Grande do Sul, advém das experiências culturais desde a escravidão. Todavia, as pesquisas sobre esses grupos avançam conforme se acentuam as descobertas das fontes e de seus usos metodológicos, dos motes teóricos e dos marcos temporais delineados para se interpretar as nuances concernentes à atuação e ao protagonismo dessas populações.

Tais agências são evidenciadas em teses, dissertações e artigos publicados no campo da História a partir da década de 1980, quando pesquisadores — de diferentes origens e pertencimentos institucionais e raciais - desenvolveram pesquisas sobre as experiências negras em tempos distintos, como aponta o artigo Fios de Ariadne (2009), de Petrônio Domingues, e o guia sobre grupos étnicos no Sul do Brasil, Negros no RS, elaborado pelo Programa de Pós-Graduação da Universidade Federal do Rio Grande do Sul (UFRGS). ${ }^{1}$ Esses estudos apresentam perspectivas diferentes e foram realizados a partir de temáticas correspondentes às conjunturas da escravidão, da abolição e do pósabolição, incluindo seus dinamismos e excetuando a objetificação. ${ }^{2}$

Por intermédio dos trabalhos citados, é possível empreender as nuances que permitem um acompanhamento da história cultural, social e política dessas populações e de suas ações de resistência à escravidão, como as fugas e a formação de quilombos; as participações nas guerras locais em um espaço de fronteira; as irmandades, o associativismo e a criação de clubes; o sindicalismo; as lutas por educação e a intelectualidade presente nas linhas da imprensa negra.

Nos estudos, em ampla escala, delineiam-se experiências que são identificadas, nessas populações, como estratégias de sobrevivência e de solidariedade, que perpassam as conjunturas e evidenciam as negociações para a criação de seus próprios espaços no pós-abolição. Além disso, analisam-se suas práticas em acontecimentos marcantes desde antes do início da república no Sul do Brasil — as agitações dos anos 1930, o

\footnotetext{
1 Sobre a bibliografia de estudos, consultar https://www.ufrgs.br/biblioestudosetnicos/rio-grande-dosul/negros/. Acesso em 13 dez.2020.

2 Dante Laytano (1958), Margaret Bakos (1982), Mario Maestri Filho (1993), Liane Muller (1999), Ana Beatriz Loner (1999), Paulo Moreira (2003), Moacyr Flores (2004), Deivison Campos (2006), Regina Célia Lima Xavier (2007), Maria Angélica Zubaran (2008), Jorge Euzébio Assumpção (2013), e mais recentemente os estudos de Lúcia Regina Brito Pereira (2008), Marcus Vinicius Freitas da Rosa (2008), José Antônio dos Santos (2000/2012), Isabel Silveira dos Santos (2010), Arilson dos Santos Gomes (2008/2014), Felipe Rodrigues Bohrer (2014), Fernanda Oliveira da Silva (2011/2017).
} 
Estado Novo, a ditadura militar e a redemocratização e as relações diaspóricas dessas populações e suas conexões nas Américas.

Este artigo tem como objetivo evidenciar a presença dos sujeitos afrodescendentes em lugares culturais e sociais da cidade de Porto Alegre, capital do Estado do Rio Grande do Sul, entre 1872 e 1971, ano da fundação da Sociedade Beneficente Floresta Aurora (SBFA) e ano da criação do Grupo Palmares de Porto Alegre, respectivamente. Esse coletivo propôs o Dia da Consciência Negra, comemorado em 20 de novembro, data que, em 2021, completa a efeméride de 50 anos desde sua primeira evocação.

Nesta narrativa, com base nos fundamentos de Henrique Cunha Júnior (2005), compreende-se por afrodescendentes as massas de trabalhadores escravizados que constituíram a mão de obra na escravidão, e consideram-se espaços socioculturais, como clubes, organizações negras, imprensa negra, empresas jornalísticas e espaços públicos. Esses lugares, em nosso entendimento, propiciaram a produção de linguagens, elaboradas pelos representantes dessas populações em conjunturas difíceis.

Criados ou frequentados por negros, os ambientes socioculturais possibilitaram a transmissão e as trocas de saberes desses indivíduos com a cultura hegemônica, de modo a tencionar as linguagens hierarquizantes e suas influências na existência das experiências e das percepções desses sujeitos. Em diversas situações, impedidos de ingressarem em espaços culturais, a alternativa foi criar espaços próprios, inclusive em épocas de comemoração do dia 13 de maio (ZUBARAN, 2008), data da abolição da escravidão no Brasil. Essa era uma alternativa viável para se fazer constituinte em uma sociedade que ignorava sua presença como cidadão da mesma forma que desconsiderava sua história, sua linguagem e sua cultura (MUNANGA, 2012).

A importância desta reflexão, que faz uso do viés decolonial, incide em ajudar a pensar em um protagonismo afrodescendente que possibilite compreender que as presenças desses sujeitos - em determinados espaços, e apesar das resistências impostas - podem ser consideradas, ao longo do período proposto, como um elemento transformador das percepções hegemônicas reproduzidas pela cultura ocidental. Além disso, destacam-se as constantes perseguições sofridas pelas matrizes africanas, consideradas práticas inferiores pelo estado e pela sociedade. Todavia, há de se considerar os espaços de resistências e as fissuras ocorridas na ordem estabelecida às práticas desses grupos. 
Nesses espaços de sociabilidades culturais, exemplificadas com rodas de samba, capoeira, maracatu, congadas e diversas religiões de matrizes africanas existentes desde a escravidão - como Terecô, Xangô do Recife, Candomblé, Batuque, Umbanda e tantas outras - tem-se a preservação das culturas afrodescendentes brasileiras. A corporeidade, os modos de "ser" e "estar" constituem-se focos de resistências nas revisões das pesquisas contemporâneas que têm instituído novas formas de olhar para o passado, como apontam Petronilha Gonçalves e Silva (2005) e Henrique Cunha Júnior (2005). Esse passado, no pós-abolição e no início da república, continuava a controlar as já referidas manifestações, impondo aos descendentes de africanos, vindos com a diáspora forçada, os desafios para a sua existência, e forçando constantes estratégias de inserção social.

As resistências dos afrodescendentes, a partir da abolição, articulam elementos políticos de afirmação e valorização em uma sociedade que decanta a mestiçagem ao mesmo tempo em que exclui sujeitos e culturas. Assim, surgem grupos e indivíduos que passam a assumir a identidade negra. Essa é referenciada como uma identidade construída culturalmente, socialmente e politicamente diante das experiências de opressão e das significações e afirmações desses sujeitos em relação à sociedade abrangente, composta por outros grupos e outras matrizes identitárias (SANTOS, 1983; GOMES, 2005).

Em Porto Alegre, a criação da SBFA, do Jornal O Exemplo (órgão da imprensa negra) e os seus articulistas, assim como a evocação do referencial simbólico à Zumbi, no início de 1970, são fundamentais para o entendimento da atuação de afrodescendentes nos espaços sociais e culturais que aqui são examinados.

Diante disso, nesta proposta, questiona-se se os representantes negros, presentes nos espaços socioculturais de Porto Alegre, resistiram à colonialidade e, se sim, quais seriam as suas atuações e proposições à afirmação de sua identidade e de sua cultura.

Entende-se que as representações relacionadas às linguagens e à presença dos corpos negros, em espaços sociais e culturais (desde o pós-abolição até o período da ditadura civil-militar), tencionaram as epistemologias ocidentais que insistiam em estigmatizar essas populações com um discurso de que o racismo e a discriminação racial não eram compatíveis com a cultura miscigenada presente no Brasil e propalada pela ideologia da democracia racial (GOMES, 2014). Por isso, na maioria das vezes, as participações das populações negras e de sua cultura, no ambiente social, ocorriam por 
meio de estratégias e agências que hibridizavam com ferramentas oriundas das culturas hegemônicas.

Por meio de bibliografia pertinente e de entrevista temática (ALBERTI, 2005) com um dos fundadores do Grupo Palmares de Porto Alegre, será examinada a atuação dos sujeitos afrodescendentes — posteriormente, assumidamente negros — em espaços socioculturais e políticos, propondo-se um exercício teórico decolonial a partir do recorte apresentado.

A proposta será apresentada em três eixos: a) reflexões sobre colonialidade, matrizes africanas e decolonialidade; b) história e atuação das populações afrodescendentes em ambientes socioculturais e c) alusão a Zumbi pelo Grupo Palmares de Porto Alegre e ações decoloniais.

\section{Reflexões sobre colonialidade, matrizes africanas e decolonialidade}

Para Boaventura de Souza Santos e Maria Paula Menezes (2009: 09), “[...] epistemologia é toda a noção ou ideia, refletida ou não, sobre as condições do que conta como conhecimento válido e é por via do conhecimento válido que uma dada experiência social se torna intencional e tangível." Nesse sentido, a elaboração do conhecimento somente existe a partir da prática dos sujeitos sociais.

A proposição da referência do Dia da Consciência Negra (representada pela data de 20 de novembro), em contraposição ao dia 13 de maio, torna-se um exemplo objetivo dessa situação, já que foi criada a partir da atuação de jovens pesquisadores vinculados às sociedades negras.

É importante destacar que, no período da colonização, as populações negras, indígenas e asiáticas eram consideradas os "outros", e tinham invalidadas as suas representações culturais a partir da mobilização de discursos morais, religiosos, filosóficos e científicos do colonizador/opressor. Esse desconsidera a existência e as práticas dos povos colonizados ao mesmo tempo em que elabora suas linguagens como verdadeiras, forjando, em cima desses povos, as noções da colonialidade.

Conforme analisado em outras oportunidades (GOMES, 2020; 2020b), a colonialidade pressupõe que os valores dispensados às vidas humanas são determinados pela pertença de vida do enunciador imperialista ocidentalizado, que "[...] se torna uma vara de medida para avaliar outras vidas humanas que não têm opção intelectual e poder institucional para contar a história.” (MIGNOLO, 2008: 293). Maria Lugones entende o 
conceito de "[...] colonialidade do ser como relacionado ao processo de desumanização.” (2014: 938). Assim, surge a hierarquização dos sujeitos e de sua cultura. As matrizes culturais africanas e suas práticas passam a ser atingidas nesse processo estabelecido pela colonialidade, instaurando os epistemicídios. ${ }^{3}$

Mesmo em suas escritas, carregadas de estigma e estereótipos sobre as populações afrodescendentes, Nina Rodrigues escreveu que “[...] de todas as instituições africanas, entretidas na América pelos colonos negros ou transmitidas aos descendentes puros ou mestiços, foram as práticas religiosas [...] as que melhor se conservaram no Brasil” (RODRIGUES, 1982: 214). Esse mesmo autor divulgou, no pós-abolição, seus registros selecionados em jornais, entre 1896 e 1905; as perseguições sofridas aos cultos afros na Bahia, considerados “focos de devassidões" pela opinião pública e pelos grupos elitistas, foi uma situação denunciada por Nina Rodrigues (18621906). À época, a polícia violava domicílios, destruía objetos e prendia, arbitrariamente, os líderes dessas matrizes (RODRIGUES, 1982: 251-252).

Destarte, as matrizes africanas correspondem a outras práticas culturais (para além da religião) com nuances festivas, à exemplo da prática cultural do Marabaixo do Amapá (CANTUÁRIO, 2020). Assim como os aspectos da corporeidade, da ancestralidade, das circularidades e das musicalidades, outros elementos, que perfazem os valores civilizatórios africanos, no Brasil, contemplam essas matrizes (SILVA, 2005; CUNHA, JÚNIOR, 2005).

Petronilha Silva (2005) usa a expressão “africanidades brasileiras" para se referir às raízes da cultura brasileira que têm origem africana. A autora destaca que essa relação está vinculada “[...] aos modos de ser, de viver, de organizar suas lutas, próprios dos negros brasileiros, e de outro lado, às marcas da cultura africana que, independentemente da origem étnica de cada brasileiro, fazem parte do seu dia a dia". (SILVA, 2005: 155).

Contudo, no período do pós-abolição, os epistemicídios presentes no Brasil, advindos com a ciência moderna, o iluminismo e o positivismo, oprimem os descendentes e as culturas de matriz africana, restando-lhes negociações e hibridizações para as suas sobrevivências e as de suas culturas, consideradas impuras, incivilizadas e

\footnotetext{
3 Segundo Sueli Carneiro (2005), o epistemicídio é um fenômeno que ocorre pelo rebaixamento da autoestima que o racismo e a discriminação provocam no cotidiano escolar pela negação aos negros da condição de sujeitos do conhecimento, por meio da desvalorização, negação ou ocultamento das contribuições do continente africano e da diáspora africana ao patrimônio cultural da humanidade, pela imposição do embranquecimento.
} 
diabólicas pela colonialidade. Apesar de essas populações, na maioria das vezes, anularem suas raízes e negarem suas identidades e culturas próprias para serem aceitos na sociedade (quando permitido), os sincretismos religiosos e as hibridizações culturais (BHABHA, 2003) possibilitaram (não sem conflitos) a sobrevivência das linguagens e das práticas afro-brasileiras percebidas com a afirmação do ser negro.

Para essas interpretações, os estudos decoloniais possibilitam novos incrementos para problematizar esse passado ainda presente. No campo epistemológico, os estudos decoloniais propõem o reconhecimento dos saberes dos povos outrora subalternizados. Segundo Maldonado Torres (2005), é o movimento de descobrimento e de revalorização das teorias e epistemologias do sul; um "giro decolonial" que significa o movimento de resistência teórico e prático, político e epistemológico à lógica da modernidade/colonialidade. (TORRES, 2005).

A opção decolonial é epistêmica, pois desvincula os fundamentos genuínos dos conceitos ocidentais de acumulação do conhecimento. Mignolo propõe substituir a geopolítica de Estado e de conhecimento de seu fundamento, na história imperial do Ocidente dos últimos cinco séculos, pela geopolítica e pela política de Estado de pessoas, línguas, religiões, conceitos políticos e econômicos e subjetividades que foram racializadas. “A opção decolonial significa aprender a desaprender." (MIGNOLO, 2008: 290). Significa (des) programar os cérebros da razão imperial e colonial.

Esse novo olhar é descortinado a partir do entendimento das resistências culturais dos povos ou sujeitos subjugados que, mesmo com a opressão, reinventam-se e resistem. Sob essa perspectiva, analisaremos, no item a seguir, as resistências dos descendentes de africanos em espaços que, via de regra, impuseram-lhes obstáculos à reprodução de suas africanidades ou de sua identidade. Contudo, em um jogo sinuoso com a sociedade abrangente, conseguiram criar mecanismos próprios para a produção de linguagens negras em uma sociedade hegemonicamente branca e ocidentalizada.

Esse “desprogramar os cérebros”, como alude Mignolo (2008), é propositivo em nossa análise, já que muitos estudos influenciados pelo materialismo da escola de sociologia da USP (BASTIDE, 1959; FERNANDES, 1978) analisaram as populações negras no pós-abolição, como se a imitação ao branco fosse a única maneira para a integração em uma sociedade competitiva e de classes. Situação descartada pela manifestação do racismo em suas diversas dimensões (ALMEIDA, 2018).

Para o objetivo do trabalho, essa situação será problematizada, pois, ao invés de simples imitação, as existências desses corpos nos espaços hegemônicos podem ser 
pensadas como uma forma de estratégia de atuação pela sobrevivência em uma sociedade hierarquizada que inferiorizou sua cultura, sua identidade e seus corpos negros.

\section{História e atuação das populações afrodescendentes em ambientes socioculturais}

Em 1872, antes da abolição da escravidão, surgiu a SBFA. Fundada na cidade de Porto Alegre, no dia 31 de dezembro de 1872, essa agremiação é considerada a sociedade negra mais antiga do Brasil. O principal objetivo da organização era zelar pela comunidade afro-gaúcha, materialmente e socialmente, auxiliando, inclusive, na realização de enterros dignos para os negros da capital (MÜLLER, 1999: 116-134). Além da manutenção da dignidade de seus mortos, o espaço realizava recreações e atividades culturais.

Com a abolição e a república, as discussões sobre raça - motivadas pelo medo das elites relacionado às massas negras livres e legitimadas pelo darwinismo social e pelo racismo científico (consubstanciado pela política do branqueamento e pelas políticas de higienização) — contribuem para a marginalização das populações afrobrasileiras (DOMINGUES; GOMES, 2013). Diante dessa situação, a luta por melhorias ficou sob a responsabilidade das próprias populações libertas e das negociações de seus representantes com o estado e a sociedade abrangente. Sendo, a ideologia de democracia racial, um importante fator de negociação (GOMES, 2017). ${ }^{4}$

Nessas circunstâncias, como já estudado em outro artigo, um setor da população negra fundou associações de diversos tipos: clubes, centros cívicos, grêmios literários, sociedades recreativas e dançantes, como a própria SBFA.

Nesse período, no Rio Grande do Sul, fundam-se jornais que, em suas linhas, denunciam e protestam contra as discriminações e visibilizam e afirmam a identidade negra.

O jornal negro O Exemplo, como aponta Maria Angélica Zubaran (2020), apareceu em Porto Alegre em 11 de dezembro de 1892, como propriedade da Irmandade da Nossa Senhora do Rosário. “O grupo de afrodescendentes que deu início

\footnotetext{
${ }^{4}$ Se por um lado a miscigenação e a democracia racial permitia a negociação com setores hegemônicos, como aduz Emília Viotti (1998), por outro desmobiliza, ao menos no campo público, a afirmação cultural da negritude. Condição observada nas comemorações do dia 13 de maio publicadas nas páginas do Jornal O Exemplo, como destacou Zubaran (2008).
} 
ao jornal estava composto por Arthur de Andrade, Marcílio Freitas, Aurélio Bittencourt Júnior, Sérgio Bittencourt, Alfredo de Souza e Esperidião Calisto" (ZUBARAN, 2020: 123).

Após alguns anos de existência, no final do século XIX, entre 1892 e 1895, o periódico fechou. O Exemplo voltou a circular no início do século XX, em 5 de outubro de 1902. Em janeiro de 1903, foi suspensa a publicação do jornal, que reapareceu em 1904 e manteve-se em atividade até 1905, quando novamente fechou. Suas atividades só reiniciaram em 1916 e, em 1930, sua publicação foi, definitivamente, encerrada (MÜLLER, 1999).

O Exemplo foi o primeiro impresso da história da comunidade negra portoalegrense; nas palavras de Zubaran (2020), o jornal “[...] trata-se de um testemunho de inestimável valor histórico e cultural para a interpretação da memória das populações afrodescendentes no pós-abolição". Nesse instante, foca-se em um dos fundadores do jornal O Exemplo, Aurélio Viríssimo de Bittencourt (1849-1919).

Para Paulo Moreira (2014), “[...] a cor de Aurélio ou a relação de sua epiderme com a sua positiva ascensão social e profissional parece ter fascinado os seus contemporâneos. Indivíduos que se autorreferenciavam como negros e fundaram periódicos voltados a defesa dos direitos deste grupo étnico.” (MOREIRA, 2014: 91). A partir dessas assertivas, constata-se que a identidade negra passa a ser uma afirmação constante nas práticas desses sujeitos. ${ }^{5}$

Moreira (2014) analisa as inserções profissionais e associativas de Aurélio, percebendo as posições ocupadas por esse indivíduo não branco em redes sociais e políticas que lhe possibilitaram ascensão e prestígio. Nas palavras de Moreira: "Percebemos que Aurélio Viríssimo de Bittencourt desde cedo constituiu uma autorrepresentação étnico-racial de pardo, percebendo-se como um indivíduo equidistante do mundo dos brancos e do cativeiro. Mundos esses nos quais convivia e circulava" (MOREIRA, 2014: 91).

Paulo Moreira (2014), ao final de seu artigo, faz uma interrogação interessante, conforme segue:

\footnotetext{
${ }^{5} \mathrm{O}$ intelectual negro Alcides Cruz, jornalista e advogado, atacado por sua cor escreveu no Jornal A Federação, impresso do Partido Republicano Rio-Grandense: "E mestiços, mulatos ou negros, como eu, legaram-me aquela virtude que Deus na sua infinda bondade entendeu dar a todos os descendentes do deserdado e misterioso continente líbico, nascidos sob um estigma que os vinte séculos do cristianismo ainda não puderam apagar, como singela compensação àqueles de quem tirara a alvinitência epidérmica o afeto" (A Federação, Porto Alegre, 12 de janeiro de 1903 Apud IHGRS). Essas atitudes demonstram o preconceito racial sofrido por esses sujeitos, assim como as suas resistências.
} 
Mas dentre várias outras indagações, resta-nos ainda uma: será a trajetória de Aurélio Viríssimo de Bittencourt suficientemente representativa para a análise de seus contemporâneos negros? Muitos responderiam que ele é um caso absolutamente atípico e sua excepcionalidade em termos de mobilidade social não lhe delegariam possibilidades de entendimento de outros de seus pares (MOREIRA, 2014: 122).

Diríamos que Aurélio, secretário do Partido Republicano Rio-Grandense de Júlio de Castilhos (1860 -1903), primeiro "presidente" do início da república no Estado, não o coloca como um caso atípico, embora obviamente não fosse a regra em uma sociedade local hegemonicamente ocidentalizada. Porém, em seu contexto, outros representantes pretos e pardos (negros, como aponta atualmente o IBGE) se destacaram.

Poucos anos depois da fundação de $O$ Exemplo, outro acontecimento com a participação de sujeitos negros merece destaque. A fundação da empresa Correio do Povo, datada de $1^{\circ}$ de outubro de 1895.

José Paulino de Azurenha foi um dos principais redatores do Correio do Povo, tendo chegado a participar da fundação do jornal, junto com Caldas Júnior (18681913), em 1895. Azurenha assinava o folhetim publicado pelo Correio todos os domingos, sob o título de "Semanário". Exercia um estilo literário que exprimia "seu torturado culto da forma", segundo a opinião de outro destacado jornalista da época, Aquiles Porto Alegre (1848-1926), que também chegou a considerá-lo "o melhor cronista literário rio- grandense" (...). Negro e "homem de jornal", José Paulino de Azurenha conquistou o respeito dos meios intelectuais e literários porto-alegrenses do seu tempo, apesar de não possuir obra exclusivamente sua publicada em vida. Segundo Alexandre Lazzari (1998), em 1881 Azurenha teria sido co-fundador de uma revista literária, junto com Aurélio Viríssimo de Bittencourt (LAZZARI, 1998: 40-41).

Outro intelectual de atuação marcante na sociedade porto-alegrense foi Arthur Rocha (1859-1888). Apesar de sua curta existência, Arthur Rocha escreveu de 12 a 14 peças de teatro, sete delas publicadas em três volumes, intitulados $O$ Teatro de Arthur Rocha, entre 1875 e 1884 (SANTOS, 2010). Arthur Rocha foi redator dos jornais $O$ Mosquito (1874), O Colibri (1877) e A Lente (1877), em Porto Alegre. Por meio de artigos políticos, contos, crônicas e peças teatrais, fazia a "crítica aos fatos sociais de seu tempo". Segundo pesquisas de Isabel Silveira dos Santos (2010), os 
contemporâneos de Arthur Rocha o classificavam como "um rapaz moreno [...] oriundo de uma estirpe, por assim dizer, ainda primitiva, ou para usar de uma comparação original, mas exata, tendo ainda a "catinga da raça" (ACHYLLES PORTO ALEGRE, 1922: 26, apud SANTOS, 2010: 06). Essa expressão “catinga da raça” denota a racialização e a hierarquização a que eram submetidos os afrodescendentes na passagem da escravidão à abolição. Contudo, mesmo com as violências cotidianas, Arhur Rocha se destacou: “[...] também ativo participante de inúmeras sociedades literárias e dramáticas em Porto Alegre como a Sociedade Dramática Romeira do Progresso, a Luso- Brasileira, a União Militar, a Filhos de Talia e outras, além de ter sido porteiro do Teatro São Pedro, em Porto Alegre [...]”' (SANTOS, 2010: 04).

Arthur Rocha, frequentemente, escrevia peças em que os sujeitos negros eram altivos e tenazes. Conforme Isabel dos Santos, Arthur Rocha, nas peças $O$ Filho Bastardo (1875), José (1878) e A Filha da Escrava (1883), destacou “[...] uma multiplicidade de representações sobre pardos, negros e mulatos, contrastando estereótipos étnico-raciais recorrentes na sociedade branca, com representações alternativas que começavam a circular entre abolicionistas da época" (SANTOS, 2010:13).

Em outro relevante trabalho, Maria Angélica Zubaran (2020) investigou as trajetórias de três médicos afro-rio-grandenses: Chagas Carvalho (1893-1958), Diógenes Baptista (1891-1962) e Arnaldo Dutra (1888-1929). A autora visibilizou o protagonismo desses três intelectuais negros, destacando as experiências compartilhadas e os diferentes posicionamentos na maneira como se inseriram social e culturalmente na sociedade gaúcha da Primeira República. Desses médicos, salienta-se a participação cultural de Arnaldo Dutra na sociedade local.

Arnaldo Dutra foi funcionário público dos Correios e Telégrafos e graduou-se médico pela Escola Médico-Cirúrgica de Porto Alegre em 1926. Igualmente, desde cedo teve participação na imprensa negra, como colaborador no jornal $O$ Exemplo. Arnaldo Dutra ocupou cargos na SBFA, inclusive o de orador oficial.

Conforme Liane Müller (1999: 129-130) a SBFA “[...] representava um cimento social para a comunidade negra porto-alegrense, com preocupações recreativas e 
beneficentes". ${ }^{6}$ A organização negra existe até os dias atuais, sendo a mais longeva do País.

Arnaldo Dutra também foi figura de destaque na cultura artística portoalegrense. Como destaca Zubaran:

\begin{abstract}
Nesse contexto, muitos afrodescendentes se dedicaram às artes, principalmente à música e ao teatro, destacando-se grande número de músicos, maestros, atores e atrizes negros em Porto Alegre. Arnaldo Dutra era um desses intelectuais e artistas, que foi presidente e ator do Grêmio Literário Dramático Arthur Rocha, ator do Conjunto teatral C.C. Rei da Pândega, músico do Grupo Musical Terror dos Falcões (1913) e presidente do bloco de carnaval Os Batutas (1922) (ZUBARAN, 2020: 138).
\end{abstract}

Um sujeito que merece destaque na década de 1920 é Pedro Elísio de Alcântara, do Centro Ethiópico e da Fraternidade Artística, considerado uma liderança operária. Segundo relatos, que merecem aprofundamentos, Pedro Elísio, natural de Pelotas, trabalhava como bilheteiro do Teatro São Pedro, conhecia ópera e era considerado um erudito por seus conhecidos. Faleceu entre as décadas de 1960 e 1970. Porém, muito ainda há para se desvendar sobre a vida desse intelectual. As evidências de sua existência são esparsas; todavia, por intermédio das pesquisas de Beatriz Ana Loner, evidencia-se, em brevíssimas passagens, a sua origem em associações negras da região sul do Estado (LONER, 2011). Fixando residência, provavelmente, no início do século XX nas proximidades de Porto Alegre. ${ }^{7}$

Quanto aos espaços culturais, teria Elísio, em sua trajetória no espaço do Teatro São Pedro, conhecido as obras ou as experiências de Arthur Rocha que atuou como porteiro daquela casa anos antes? Difícil de saber. Todavia, as presenças desses sujeitos, nesse espaço sociocultural, evidencia a circularidade dos afrodescendentes em um importante ambiente cultural das elites locais.

\footnotetext{
6 A SBFA também fazia atividades políticas. A partir de 1910, emprestava seus salões de festas para reuniões de entidades profissionais como a Aliança Operária e a União de Estivadores.

7 Além dessas informações bibliográficas, foram localizados vestígios de Pedro Elísio de Alcântara como servidor do Arquivo Público de Rio Grande do Sul (APERS), de Porto Alegre. No processo número 8566, datado de 1946, em que pede licença médica, localiza-se informações de que Elísio era servente do Arquivo. Em um outro processo localizado no acervo da instituição, sob o número 2136, de 1947, consta que Elísio solicita ao diretor do APERS aposentadoria, e logo depois desiste (Catálogo Apers, 2019). Por meio destes documentos é possível enfatizar que Elísio circulou em espaços relevantes da cidade, já que um arquivo é um espaço fundamental na guarda dos registros documentais da sociedade.
} 
Nesse tópico, outros dois médicos negros envolvidos com a cultura portoalegrense foram Luciano Raul Panatieri (1897-1972) e Veridiano Farias (1906-1952). Panatieri, formado pela universidade pública do Rio Grande do Sul, em 1922, foi redator da imprensa negra no final da década de 1920. Utilizando o seu senso criativo e intelectual, escreveu a favor da conscientização e da integração da identidade negra. Mais especificamente, atuou no periódico O Exemplo (1892-1930) e no jornal O Astro (1927-1928) de Cachoeira do Sul. O intelectual participou da fundação do Centro Riopardense de Letras. Já Veridiano Farias, formado pela Faculdade de Medicina da UFRGS, em 1951, teve destaque no carnaval. Com seus conhecimentos sobre música, foi importante na história dos grupos carnavalescos da cidade. Como ensaiador dos "Prediletos", costumava se reunir com a comunidade nos bares do Areal da Baronesa, no Bairro Cidade Baixa (GOMES, 2016).

Destaca-se que, em 1958 - seis anos após o falecimento de Veridiano Farias a SBFA, em conjunto com o governo do Estado, organizou o Congresso Nacional do Negro, que tem como conclusão "[...] a campanha nacional de alfabetização das populações negras" (GOMES, 2008). O evento, que teve ampla repercussão regional, traz no seu bojo a preocupação da agremiação com a articulação política, com o objetivo de se projetar e de atualizar suas históricas ações a favor das populações desprovidas.

Antes de adentrar no próximo tópico, convém informar que os representantes negros brasileiros - a exemplo de suas organizações no pós-abolição até praticamente a década de 1970 - eram integracionistas e propunham a educação e a instrução como meio para se inserirem a sociedade, não tendo como estratégia a denúncia sistemática do racismo, embora existissem protestos (GOMES, 2008).

Essa situação será alterada, paulatinamente, nas décadas posteriores, em virtude da falta de oportunidades e de acesso oriundos da discriminação e do racismo à brasileira. Essa mudança será pontuada pelos intelectuais negros e negras que passam a estudar, na década de 1970 e no início de 1980, academicamente, o fenômeno que persistia em dificultar a transformação da realidade desses sujeitos (GONZALES; HASENBALG, 1982).

O racismo e a discriminação são identificados como o grande problema nacional a ser enfrentado epistemológica e politicamente (GONZALES, 1988). E, nessa linha, o Rio Grande do Sul tem destaque na projeção da proposição do Dia da Consciência Negra. Além de protestar contra os elementos da colonialidade, era preciso, 
estrategicamente, propor a valorização da cultura negro-africana, do orgulho negro, bem como evidenciar que a democracia racial não passava de mero mito. Era a cultura a serviço da consciência, levada adiante no ambiente sociocultural do Grupo Palmares.

\section{A alusão a Zumbi pelo Grupo Palmares de Porto Alegre e as ações decoloniais}

O Grupo Palmares foi fundado em 1971 em Porto Alegre. Tinha como escopo a revisão da história do Brasil para desvelar a "tradição de resistência", a fim de recuperar a autoestima étnica e, com isso, tirar a maioria dos negros do imobilismo político e da acomodação social aos espaços concedidos por uma sociedade, segundo o grupo, desigual (CAMPOS, 2006: 09). ${ }^{8}$

Em seu estudo pioneiro, Deivison Campos (2006) destacou sobre o Grupo Palmares:

Ao afirmar-se e organizar-se como grupo étnico, adotam uma postura e um discurso subversivo que coloca em cheque conceitos estruturantes da sociedade brasileira como democracia racial, identidade e cultura nacional [...] enfrentaram a ditadura ao organizarem-se como movimento contestador por melhores condições sociais e econômicas, e por mais espaço político (CAMPOS, 2006: 05).

O Grupo Palmares tinha como proposta social e cultural a valorização do dia 20 de novembro, data da morte de Zumbi dos Quilombos dos Palmares (1695), como principal referência para os negros sul-rio-grandenses em contraponto às comemorações do dia 13 de maio (1888), dia oficial da abolição da escravidão no Brasil.

Antônio Carlos Cortês, um dos fundadores do Grupo, em recente artigo, intitulado Os esquecidos do 20 de novembro, dia da consciência negra (2020), destacou a origem das ideias dos jovens intelectuais negros em propor um novo referencial simbólico à data da abolição:

\footnotetext{
${ }^{8}$ A agremiação nasce inserida em uma tradição centenária instaurada pelas populações negras antes mesmo da abolição, identificada na formação de círculos, clubes, impressos e confrarias fundadas por negros em Porto Alegre e no interior do Estado (MÜLLER, 1999 LONER, 1999; SANTOS, 2000; PEREIRA, 2008; SILVA, 2011).
} 
[...] Nos anos 70, quatro universitários negros decidiram rever a história. A proposta era recriar data comemorativa em confrontação ao 13 de Maio, dia da abolição da escravatura. Para a comunidade afrodescendente, o 20 de Novembro era data que melhor representava a história real dos negros brasileiros. Estes jovens, fundadores ajudaram a instituir o Dia da Consciência Negra (CORTÊS, OS ESQUECIDOS..., 2020, sp). (Grifos nossos).

Além da visibilidade da história real enunciada por Cortês (2020), de acordo com José Augusto Zorzi (2019), tem-se, nas palavras dos líderes da organização, um outro elemento a se destacar, vinculado à situação cotidiana vivenciada pelos negros após o dia 13 de maio de 1888.

Um dos objetivos centrais da evocação desta data era deslocar as comemorações do treze de maio, data em que se lembra o fim formal da escravidão no Brasil, para uma data que deveras celebrasse o legado e o passado negro no país. Como o próprio Oliveira Silveira afirmou [Um dos líderes do Grupo], ${ }^{9}$ a abolição só havia ocorrido no papel, sem medidas práticas que amenizassem a situação do negro no "pós libertação". Logo, o 13 de maio não tinha porquê ser comemorado.

Para o debate da ideia da história real e dos problemas enfrentados pelas populações negras, além do deslocamento das comemorações das datas - considerado, nesta análise, como uma operação decolonial - existe o aspecto da reprodução da linguagem e da cultura no cotidiano, além da discriminação racial, que são situações que devem ser refletidas, como o observado nas escritas de Antônio Carlos Cortês (2020).

Por meio de sua trajetória de vida, um dos fundadores do grupo nos traz as considerações da história oficial, o que era entendido por real, na sua concepção, e como a data da abolição era comemorada e ensinada nas escolas.

\footnotetext{
${ }^{9}$ Oliveira Ferreira Silveira (1941-2009) foi poeta e escritor. É considerado um dos expoentes da data alusiva à memória da luta negra para a morte de Zumbi dos Palmares (1655-1695). Para saber mais sobre o Poeta ver o Projeto de Extensão "Poeta Oliveira Silveira: digitalização e conservação de sua vida e obra" lançado no dia 20 de novembro de 2020 em alusão aos cinquenta anos do 20 de novembro. Disponível em:<www.ufrgs.br/oliveirasilveira>. Acesso em 19 dez.2020.
} 
Sobre a história oficial e a real, Cortês explica que a Lei Áurea de 1888 dizia o seguinte:

Artigo $1^{\circ}$ dizia que ficava abolida a escravidão no Brasil. Segundo $\left(2^{\circ}\right)$, revogam-se as disposições em contrário. Justificativa sequer existia, ou seja, excluíram a mão de obra do escravizado e o abandonou a própria sorte. Foi durante as discussões do grupo, que descobri o livro Quilombo dos Palmares, de Edison Carneiro. Após estudar junto a outras obras o movimento decidiu pelo 20 de Novembro, dia da morte de Zumbi dos Palmares (CORTÊS, OS ESQUECIDOS..., 2020, sp) (Grifo do autor).

Compreende-se que, para Cortês, existiam outras possibilidades que poderiam ser representadas na narrativa histórica, para além da data elaborada pelo Estado brasileiro, que rememorava a libertação dos escravizados a partir da assinatura da Lei Áurea pelas mãos da Princesa Isabel. E esse contraponto, identificado como real, era fundamentado em pesquisas aprofundadas, realizadas por Edison Carneiro (1912-1972), considerado um dos pioneiros sobre a trajetória dos Quilombos dos Palmares. ${ }^{10}$

Do lado oficial, como aduz Zorzi (2019), o dia 13 de maio, desde 1893, passou a ser denominado o dia da "Fraternidade dos Brasileiros". "A própria nomenclatura da data - "fraternidade dos brasileiros" - revela uma interpretação pacifista da memória daquele episódio. Não necessariamente teria que ser esse o objetivo dos que marcaram tal data neste formato, mas ela parece reforçar uma ideia de integração dos brasileiros [...]" (ZORZI, 2019: 37).

Retornando às ideias de Cortês (2020), ao estudar outras obras, em contraponto à história e às datas oficiais, os líderes do Grupo Palmares passam a conhecer as lutas dos quilombolas pela conquista da liberdade. Era a "fraternidade" fabricada versus a pesquisa histórica para transformar a história ensinada e a realidade vivenciada.

A história pesquisada, na concepção do grupo, é a que representava o protagonismo negro. Essa era a história que, de fato, poderia permitir a conscientização da importante participação das populações negras como agentes de sua história, e não como meros expectadores do dia da libertação ou nas relações sociais cotidianas de uma

\footnotetext{
${ }^{10}$ Edison Carneiro. Carneiro nasceu em Salvador em 1912 e faleceu na cidade do Rio de Janeiro no ano de 1972. Foi o pioneiro nas pesquisas sobre o Quilombos dos Palmares, tendo publicado o livro: $O$ Quilombo dos Palmares. Editora Brasiliense: São Paulo, 1947, com nova edição em 1958.
} 
dita harmonia racial, que não passava de mero e hierarquizante mito. Nas escritas de Antônio Carlos Cortês:

Lembro que as escolas sul rio-grandenses realizavam festejos no dia da abolição e crianças negras sofriam piadas, o que geralmente acabavam em brigas. Eram recorrentes comentários: "vocês não são nada, seus coisas"! Havia escolas que apresentavam peças de teatro em que as crianças negras faziam papel de escravizados prestando homenagens à princesa Isabel (CORTÊS, OS ESQUECIDOS..., 2020, sp).

Com o intuito de contar a história pelo prisma dos grupos que foram outrora colonizados, o grupo inicia o movimento de resistência teórico e prático, político e epistemológico, à lógica da modernidade/colonialidade (TORRES, 2005) contra a hegemonia do 13 de maio e a ideia de democracia racial (GOMES, 2005). Por isso, a cultura era um aspecto importante na arena pública, de modo a possibilitar outros saberes e conhecimentos à sociedade. De acordo com Deivison Campos (2006):

O Grupo Palmares surgiu em 20 de julho de 1971, organizado como uma associação cultural, sem fins lucrativos e com duração indeterminada, segundo projeto de estatuto 12 redigido para o grupo. A proposta de ação apresentada era a de 'promover estudos sobre história, artes e outros aspectos culturais, particularmente em relação ao negro e ao mestiço de origem negra. A partir dos estudos, seriam realizadas apresentações e atividades públicas para atingir maior visibilidade junto ao espaço social' (CAMPOS, 2006: 54).

Para atingir a visibilidade, o Grupo escreve as suas propostas em jornais de grande circulação do Rio Grande do Sul. Conforme Deivison Campos (2006), o grupo utilizou-se de estratégias para se legitimar, encontrando, na imprensa, uma forte aliada para seus propósitos: “A utilização da imprensa visava, neste primeiro momento, a comprovar a existência e fortalecer a presença de personagens históricos negros frente à 
sociedade, pois, segundo o discurso do grupo, a história oficial buscava omiti-los (...)" (CAMPOS, 2006: 58). ${ }^{11}$

As estratégias deram certo, já que, a partir de 1972, a data passa a ter repercussão em setores da mídia regional e nacional, a ponto de o 20 de novembro se tornar um referencial à consciência negra contra um significado de que, no Rio Grande do Sul e no País, existisse uma fraternidade entre as raças, enquanto as populações negras eram ensinadas a fazer papel de escravizados na escola em comemorações ao dia 13 de maio. A partir dessa situação, constata-se a reprodução da hierarquização dos sujeitos e de sua cultura, processos instaurados pela colonialidade.

O grupo, consciente dos epistemicídios impostos aos saberes afro-brasileiros, realizava inúmeras atividades culturais a fim de ressignificar a história e a linguagem das matrizes africanas. Samba, culinária, poemas e verbetes eram utilizados como formas de transmissão crítica e aprofundada de conhecimentos. Além disso, como o identificado em diversos indivíduos citados neste artigo, seus integrantes também foram membros da SBFA, fundada em 1872, como destaca Antônio Carlos Cortês em entrevista:

Arte e Cultura (foram) importante no Grupo Palmares, eis que eu e Jorge Xangô éramos do Grupo de Teatro da Sociedade Floresta Aurora fundada em 1872. Como integrante eu via a Escola de Samba como a maior fonte inesgotável de cultura, por seu enredo, esculturas, alas em evolução, coloridos nas fantasias, coreografia espontânea ao som do samba. A par de tudo isto ressaltávamos que o churrasco era invenção do negro, bem como a feijoada e o mocotó e tantos outros pratos da culinária africana. Na literatura todos amavam a poesia de autores negros. Eu recitava Navio Negreiro do Castro Alves. Criticávamos os dicionaristas com seus verbetes racistas: lista negra, câmbio negro, setembro negro, negrito, buraco negro, ovelha negra e tantos outros (CORTÊS, Entrevista, 23 de novembro de 2020). ${ }^{12}$

Como pertencer a uma identidade que, historicamente, foi criada pelo colonizador e que, pela colonialidade, legou a esse grupo a relação da sua cultura com

\footnotetext{
${ }^{11}$ Aqui faço referência a Deivison Campos em sua pesquisa, que informa: Nesse período, “[...] têm-se dois manifestos. Um redigido em 1972 e publicado em Zero Hora (REVISTA ZH, 1972: 05), em um caderno especial sobre Zumbi e os Palmares, e o outro em 1974, veiculado no Jornal do Brasil." (GARCIA, 1974, s.p. Apud CAMPOS, 2006: 58-59).

12 Em virtude da pandemia do coronavírus, a entrevista foi realizada por e-mail.
} 
tudo que existe de ruim? Como parar esse epistemicídio? A cultura e a linguagem passam a serem utilizadas pelos jovens intelectuais negros para dar sentido de conscientização da opressão, da valorização da autoestima à transformação da realidade imposta à comunidade. Em suas ações, são acionadas as africanidades brasileiras (escolas de samba, culinária africana, poesia negra etc.) como resistências à colonialidade.

Questionado sobre como o grupo refletia a democracia racial, nosso entrevistado respondeu de maneira contundente: "Entendiamos que o Brasil só seria democracia racial quando o fosso da desigualdade social acabasse." (CORTÊS, Entrevista, 23 de novembro de 2020).

Todavia, ao propor um novo referencial simbólico ao Dia da Consciência Negra, esses sujeitos estabeleceram um "giro decolonial” (MIGNOLO, 2018), representado na ressignificação do dia 20 de novembro:

O Grupo Palmares encerrou as atividades no fim da década de 1970, porque, o objetivo dos ativistas já havia sido alcançado. Em seguida, a causa foi assumida pelo Movimento Negro Unificado (MNU), que, com base nas pesquisas dos sul-rio-grandenses, oficializou a data. Em 1978, o escritor paulista Osvaldo de Camargo, em evento realizado pelo MNU, em Salvador, propôs que 20 de novembro fosse o Dia da Consciência Negra (CORTÊS, OS ESQUECIDOS..., 2020, sp).

$\mathrm{Na}$ perspectiva deste artigo, foram ações decoloniais a proposta do Grupo Palmares de proposições e revisões da história, com atuação na realidade, e o desmascaramento da democracia racial para crítica aos estereótipos coloniais. A opção decolonial é epistêmica, pois desvincula os fundamentos genuínos dos conceitos ocidentais de acumulação do conhecimento.

Esse novo olhar é descortinado a partir do entendimento das resistências culturais dos grupos ou sujeitos subjugados que, mesmo com a opressão — passada e atual — reinventam-se e resistem (GOMES, 2020).

\section{Considerações finais}


A modernidade/colonialidade legou às populações afrodescendentes estereótipos que, mesmo após a abolição, insistiam em manter sua cultura e sua história — sob a régua da cultura ocidental — como inferior. A partir de uma hierarquia construída por meio da linguagem, e que encontrava eco na realidade, essas populações passaram a elaborar ações práticas como alternativa com vistas a transformar o seu cotidiano de exclusão.

As experiências investigadas por uma ampla historiografia - elaborada antes e após a criação dos programas de pós-graduação de História de Porto Alegre e do Estado do Rio Grande do Sul — apontam à essa direção a partir da década de 1980.

Os afrodescendentes, em Porto Alegre, resistiram à colonialidade de maneira estratégica, participando de associações, como redatores da imprensa, atuando em ambientes intelectuais e socioculturais, e criando seus próprios espaços, jornais e associações.

Assim, difundiram suas ideias, apresentando alternativas à sobrevivência e, posteriormente, ao reconhecimento de sua identidade assertiva. Desde as demandas por locais para que fossem dignamente enterrados, como a SBFA propôs desde o seu início (1872), até a ressignificação da data alusiva a libertação dos escravizados, formulada pelo Grupo Palmares (1971), as propostas intercalavam demandas de acesso à educação e ao combate ao racismo.

Ainda que, em um primeiro momento, as ações desses indivíduos e grupos visassem a uma integração, em uma sociedade decantada como harmônica (em que conviviam, pacificamente, brancos, negros e índios, como apregoava a ideologia da democracia racial), com o tempo, estrategicamente suas reivindicações vão afunilando, "girando" para a afirmação das especificidades de uma identidade negra política e para o reconhecimento positivo da cultura elaborada por esses sujeitos desde a África.

Aos olhos da colonialidade, instaurada a partir da modernidade, os descendentes dessas populações eram considerados inumanos, e suas culturas eram associadas a incivilidade, primitivismo e mal, maniqueísmo advindo do cristianismo. Em contrapartida, a cultura ocidental, ocorrida com as "conquistas europeias", e insuflada de moralidade, filosofia e racionalismo, garantiria a civilidade e o desenvolvimento dessas culturas de modo a se ocidentalizarem ou a "branquearem".

Essa situação, antes e depois da promulgação da república no Brasil, em que o racismo científico é obliterado (mas, nem tanto) pelo discurso da harmonia racial e da mestiçagem, passa, definitivamente, a nortear os interesses políticos da nação. Inclusive 
por medo das elites, para estabilizar e controlar um país de maioria negra. Esse momento foi percebido por indivíduos afrodescendentes como uma oportunidade para evidenciar os problemas enfrentados por meio da imprensa negra. Um contexto em que as matrizes africanas continuavam a ser perseguidas.

Antes da criação de seus espaços, esses grupos frequentavam teatros e redações jornalísticas da sociedade hegemônica de maneiras ambivalentes, pois, embora aceitos (se aceitos), provavelmente, eram minorias e seu corpo e sua cultura eram recebidos com desconfianças. Por isso, tendiam a reproduzir os referenciais das culturas preponderantes, identificadas à europeia. Todavia, mesmo dentro desses espaços, no final do século XIX, Paulino Azurenha, com o codinome "Léo Pardo", escrevia colunas críticas sobre os carnavais porto-alegrenses no periódico Correio do Povo. Assim como Pedro Eliso, outro afrodescendente muito respeitado pelos frequentadores do Teatro São Pedro por sua erudição cultural e reconhecida envergadura no conhecimento das óperas italianas, francesas e alemãs entoadas no palco.

Na mesma época, o jornal $O$ Exemplo já anunciava, por meio de intelectuais pardos, letrados, políticos e médicos, a importância da educação para as populações pobres que, não por acaso, em sua maioria eram afrodescendentes. Esses representantes comemoravam o dia 13 de maio, que, em 1893, fora oficialmente decretado como o dia da "Fraternidade dos Brasileiros". Porém, quando possível, acusavam a sociedade abrangente pelos estigmas enfrentados por essas populações, e afirmavam as suas diferenças étnicas em meio à percepção dos intelectuais comumente aceitos, como é evidenciado em Aurélio Viríssimo Bittencourt. Educação, teatro e grupos de estudos eram a tônica de muito desses representantes, que, inclusive, tiveram em comum suas participações nos quadros da SBFA. Essa situação é identificada no O Exemplo até o encerramento na década de 1930, quando os intelectuais afrodescendentes também eram membros da SBFA. Aliás, essa sociedade, reconhecendo a importância das surgidas posteriormente - Club Náutico Marcilio Dias e Associação Satélite Prontidão demonstrou-se basilar na origem a na atuação das populações afrodescendentes da cidade desde a sua criação no ano de 1872.

Na década de 1950, já com a construção política e cultural da identidade negra visibilizada e atuante na arena pública, foi realizado o Congresso Nacional do Negro de Porto Alegre (1958), com representantes das associações negras do Estado e do Brasil. A SBFA e seus intelectuais, em conjunto com o governo do Rio Grande do Sul, foram os organizadores do evento. No conclave, debateu-se o analfabetismo existente no 
Brasil que atingia as populações negras (GOMES, 2008). Nesse contexto, a principal demanda era a integração à sociedade nacional, tendo, na educação, a esperança para as tão sonhadas oportunidades. A luta era por aceitação de sua cultura e pela inclusão nos espaços de ensino. A luta não era, necessariamente, pelo respeito à diferença, mas sim, pela igualdade dentro de uma estrutura ocidentalizada em que a história dessas populações continuaria silenciada e estigmatizada.

Contudo, nas décadas seguintes, mesmo em um estado de exceção advindo com os anos de chumbo da ditadura civil-militar brasileira, intelectuais jovens negros portoalegrenses passam a propor novos referenciais, entendidos, aqui, como decoloniais. Jovens que, por vínculo à afrodescendência e à identidade negra, assim como os demais intelectuais identificados nesse trabalho, frequentaram os históricos salões da SBFA. Entretanto, já nos anos 1970 do século XX, a história real da libertação não era representada pela assinatura da Lei Áurea por Isabel, mas, sim, pelas resistências guerreiras de Zumbi à liberdade. Por isso, a proposta do dia 20 de novembro estaria em consonância com a desalienação das populações negras de sua realidade, percebida pelos membros do grupo como um convívio em que a discriminação, o racismo e a falta de oportunidades efetivamente ocorriam. No ensino, por exemplo, as escolas reproduziam as crianças afrodescendentes como "escravos" por meio de encenações teatrais.

Para Deivison Campos, as ações do Grupo Palmares se constituíam como práticas subversivas, já que eram realizadas no período autoritário, época em que a reificação da democracia racial era uma normativa. Para nós, a atuação do Grupo Palmares, além de subversiva, foi decolonial.

A partir desse momento, no início da década de 1970, as reivindicações não ocorrem pela inclusão via participação na cultura hegemônica, e sim por uma participação ativa em que a história e a cultura afrodescendente, elaboradas por intelectuais assumidamente negros, portassem significados decoloniais de modo a derrubar estigmas. Situação evidenciada nas linhas da imprensa negra contemporânea, com destaque para a Revista Tição de Porto Alegre, editada por Vera Daisy Barcellos.

O carnaval, a culinária e os sambas ensinam histórias e preservam tradições, assim como as palavras necessitam ser criticadas. As representações negras, pejorativadas, emitidas pela colonialidade, deveriam ser revistas, uma vez que, para os representantes do Grupo Palmares, os verbetes racistas deveriam ser atacados e a data 
da libertação, por meio da consciência negra, projetada em Zumbi. "O lado negro da força" passa a ser tencionado como algo positivo.

O Grupo Palmares encerrou suas atividades em 1978. A ressignificação e a práxis decolonial proposta pela associação teve impacto profundo na cultura, na sociedade e na atuação política das populações negras porto-alegrense, sul-riograndenses e nacionais. Em 2021, essa data completará 50 anos.

Trata-se de uma iniciativa que tensionou a narrativa histórica e a elaboração de novos referenciais simbólicos e conhecimentos válidos, atinentes à representação da consciência negra. Elementos discursivos que aparecem nas linhas de leis e normas de estado. A legislação de ensino (Lei $n^{\circ} 10.639 / 2003$ ) coloca no calendário escolar o dia 20 de novembro como o Dia Nacional da Consciência Negra. As Diretrizes Curriculares para a Educação das Relações Étnicos Raciais (Parecer n 03/2004) citam Zumbi como representante da luta social. A Lei $\mathrm{n}^{\mathrm{o}}$ 12.519/2011, em seu artigo $1^{\mathrm{o}}$, institui “[...] o Dia Nacional de Zumbi e da Consciência Negra, a ser comemorado, anualmente, no dia 20 de novembro, data do falecimento do líder negro Zumbi dos Palmares”.

De acordo com o levantamento publicado pelo jornal Folha de São Paulo de 20 de novembro de 2017, como demonstra José Zorzi (2019: 82), o "Dia da Consciência Negra era celebrado em 1.045 cidades em todo o Brasil”, com algumas cidades comemorando feriados e outras não.

Além disso, as tônicas dessas comemorações e legislações são a elevação da autoestima, da luta contra o racismo e as discriminações. Assim, como nas universidades, as revisões das narrativas históricas ocorrem por meio de núcleos de estudos afro- brasileiros, de grupos de pesquisas e de trabalhos escritos por negros e não negros, dedicados a transformar paradigmas.

Quanto à centenária SBFA, essa continua, materialmente, existindo na cidade (apesar das mudanças constantes de sede, advindas da pressão das elites locais) e resistindo, em época de avanços conservadores, motivando a atuação dos sujeitos em espaços socioculturais contra o epistemicídio à produção de uma história decolonial.

\section{Fontes}

Catálogo Secretaria do Interior e Exterior: o Arquivo Público do RS e seus processos administrativos [livro eletrônico] (2019). In FERNANDES, Letícia Wickert \& PORTELLA, Viviane Portella de. Porto Alegre: APERS. Disponível em: <https://www.apers.rs.gov.br/upload/arquivos/202006/01160821-catalogo-sjapers-e-processos-administrativos.pdf>. Acesso em: 07 de dez.2020. 


\section{Referências bibliográficas}

ALMEIDA, Silvio Luiz de (2018). O que é racismo estrutural? Belo Horizonte: Letramento.

ASSUMPÇÃO, Jorge Euzébio (2013). Pelotas: Escravidão e Charqueadas (1780-1888). Passo Fundo: FCM Editora.

BASTIDE, Roger; FERNANDES, Florestan (1959). Brancos e Negros em São Paulo. São Paulo: Companhia Editora Nacional.

BHABHA, Homi (2007). O local da Cultura. Editora UFMG: Belo Horizonte.

CAMPOS, Deivison Moacir Cezar (2006). O Grupo Palmares (1971-1978): Um movimento negro de subversão e resistência pela construção de um novo espaço social e simbólico. Dissertação (Mestrado em História). PPGH-PUCRS, Porto Alegre.

CANTUÁRIO, Victor André Pinheiro (2020). Marabaixo: Patrimônio cultural imaterial do Amapá. Fênix - Revista De História E Estudos Culturais, vol. 17, n.1), pp. 103-117. Disponível em: s https://www.revistafenix.pro.br/revistafenix/article/view/49>. Acesso em: 09 de dez.2020.

CARNEIRO, Edison (1958). O Quilombo dos Palmares. São Paulo: Brasiliense.

CARNEIRO, Sueli (2005). A Construção do Outro como Não-ser como fundamento do Ser. São Paulo: FUESP.

CORTÊS, Antônio Carlos (2020). Entrevista concedida a Arilson dos Santos Gomes. Correio eletrônico, Porto Alegre.

CORTÊS, Antônio Carlos (2020). Os esquecidos do 20 de novembro dia da consciência negra. Jornal do Comércio. Porto Alegre. Disponível em: <https://www.jornaldocomercio.com/_conteudo/opiniao/2020/11/767096-osesquecidos-do-20-de-novembro-dia-da-consciencia-negra.html>. Acesso em: 24 de nov. 2020.

COSTA, Emilia Viotti. Da Monarquia à República - Momentos decisivos. São Paulo: Editora UNESP, 1998.

DOMINGUES, Petrônio (2009). Fios de Ariadne: o protagonismo negro no pósabolição. Anos 90, Porto Alegre, v. 16, n. 30, pp. 215-250. Disponível: s https://seer.ufrgs.br/anos90/article/view/18932/11021>. Acesso em 13 de dez.2020.

FERNANDES, Florestan (1978). A Integração do Negro na Sociedade de Classes. São Paulo: Ática.

FLORES, Moacyr (2004). Negros na Revolução Farroupilha. Porto Alegre: EST.

GOMES, Arilson dos Santos (2008). A formação de oásis: dos movimentos frentenegrinos ao Primeiro Congresso Nacional do Negro em Porto Alegre - RS (1931-1958). Dissertação. (Mestrado em História). PPGH/PUCRS, Porto Alegre.

GOMES, Arilson dos Santos (2020). A Unilab e as políticas de ações afirmativas para a promoção da igualdade étnico-racial. In. Unilab 10 anos. LIMA, Ivan Costa; ODILA, Artemisa (Orgs). (Prelo).

GOMES, Arilson dos Santos (2020b). A pandemia da Covid-19 e as suas implicações na reprodução do racismo estrutural no Brasil e no mundo (Prelo).

GOMES, Arilson dos Santos (2014). O universo das gentes do mar e a identidade negra nos discursos e práticas políticas de Carlos Santos (1959-1974). Tese (Doutorado em História) PPGH/PUCRS, Porto Alegre.

GOMES, Arilson dos Santos (2017). Organizações sociais e afirmação negra brasileira (1888 - 1978). Revista Identidade, São Leopoldo, v. 22 n. 2, p. 172-189, jul.-dez. 
Disponível

em:

$<$

http://periodicos.est.edu.br/index.php/identidade/article/view/3182>. Acesso em: 20 nov. 2020.

GOMES, Arilson. Luciano Raul Panatieri e Veridiano Farias: a trajetória de dois médicos negros sul-rio-grandenses (2016). In: QUEVEDO, Éverton Reis; POMATTI, Angela Beatriz (Orgs.). Museu de História da Medicina - MUHM: Um acervo vivo que se faz ponte entre o ontem e o hoje. Porto Alegre: Evangraf, v. 01, pp. 156-71.

GOMES, Flavio dos Santos; DOMINGUES, Petrônio (2013). Raça, Pós-Emancipação, Cidadania e modernidade no Brasil. In__: Da nitidez e invisibilidade - Legados do pós-emancipação no Brasil. Belo Horizonte: Fino Traço.pp.305-325.

GOMES, Nilma Lino (2005). Alguns termos e conceitos presentes no debate sobre relações raciais no Brasil: uma breve discussão. In: Coleção educação para todos. Brasília, DF: SECAD/MEC, pp.39-62.

GONZALEZ, Lélia (1988). A categoria político-cultural de amefricanidade. In: Tempo Brasileiro. Rio de Janeiro, n. 92/93 (jan./jun.), pp. 69-82.

GONZALEZ, Lélia; HASENBALG, Carlos (1982). Lugar de Negro. Rio de Janeiro: Marco Zero.

IHGRS (2017). Mestiço, mulato ou negro [recurso eletrônico] / Alcides Cruz. Organizado por: Instituto Histórico e Geográfico do Rio Grande do Sul - Dados eletrônicos - Porto Alegre: Instituto Histórico e Geográfico do Rio Grande do Sul.

JÚNIOR, Henrique Cunha. Nós afrodescendentes: história africana e afrodescendente na cultura brasileira. In ROMÃO, Jeruse (Org) (2005). História da Educação do Negro e outras histórias. Brasília: SECADI/ MEC. pp.249-273.

LONER, Beatriz Ana. Antônio: de Oliveira a Baobad (2011). In: GOMES, Flávio; DOMINGUES, Petrônio (Orgs). Experiências da Emancipação: biografias, instituições e movimentos sociais no pós-abolição (1890-1980). São Paulo: Selo negro. pp.109-136.

LONER, Beatriz Ana (1999). Classe Operária: Mobilização e Organização em Pelotas: 1888- 1937. Tese (Doutorado em Sociologia), UFRGS, Porto Alegre.

LUGONES, Maria. Rumo a um feminismo descolonial. Estudos Feministas; Florianópolis, v. 22, n. 3 (2014).

MAESTRI. Mario (1993). O escravo gaúcho - resistência e trabalho. Porto Alegre: Editora UFRGS.

MIGNOLO, Walter (2008). Desobediência epistêmica: a opção descolonial e o significado de identidade em Política. Trad. Ângela Lopes Norte. Cadernos de Letras da UFF - Dossiê: Literatura, língua e identidade, nº 34, pp. 287-324.

MOREIRA, Paulo Roberto Staud. (2014). O Aurélio era preto: trabalho, associativismo e capital relacional na trajetória de um homem pardo no Brasil Imperial e Republicano. Estudos Ibero-Americanos, vol 40, n.1, pp. 85-127. Disponível em: $<$

https://revistaseletronicas.pucrs.br/ojs/index.php/iberoamericana/article/view/165 04>. Acesso em: 18 nov. 2020.

MOREIRA, Paulo Roberto Staudt (2003). Os cativos e os Homens de Bem Experiências Negras no Espaço Urbano - 1858-1888. Porto Alegre: EST.

MÜLLER, Liane Suzan (1999). "As contas do meu rosário são balas de artilharia" Irmandade, jornal e sociedades negras em Porto Alegre 1889-1920. Dissertação (Mestrado em História), PPGH/PUCRS, Porto Alegre.

MUNANGA, Kabengele (2012). Negritude: usos e sentidos. Belo Horizonte: Autêntica. 
PEREIRA, Lúcia Regina Brito Pereira (2008). Cultura e Afrodescendência: Organizações Negras e suas estratégias educacionais em Porto Alegre (18722002). Tese (Doutorado em História). PPGH/PUCRS, Porto Alegre.

QUIJANO, Aníbal (2005). Colonialidade do poder, eurocentrismo e América Latina In

LANDER, Edgardo. A colonialidade do saber: eurocentrismo e ciências sociais perspectivas latino-americanas. Colección Sur Sur, Buenos Aires, Argentina: CLACSO.

RODRIGUES, Nina (1982). Os africanos no Brasil. São Paulo: Ed.Nacional, Universidade de Brasília.

ROSA, Marcus Vinicius Freitas da. Quando Vargas caiu no samba: um estudo sobre os significados do carnaval e as relações sociais estabelecidas entre os poderes públicos, a imprensa e os grupos de foliões em Porto Alegre durante as décadas de 1930 e 1940. Dissertação (Mestrado em História) UFRGS, Porto Alegre.

SANTOS, Boaventura de Sousa; MENESES, Maria Paula (Orgs.) (2009). Epistemologias do Sul. São Paulo: Cortez.

SANTOS, Isabel Silveira dos (2010). Arthur Rocha: Um Intelectual Negro no "Mundo dos Brancos". Anais do X Encontro Estadual de História, ANPUH-RS. Disponível

em: <http://www.eeh2010.anpuhrs.org.br/resources/anais/9/1279496410_ARQUIVO_ arthurrochaumintelectualnegrono mundodosbrancos.pdf $>$. Acesso em: 30 de ago.2014.

SANTOS, José Antônio dos (2000). Raiou "A Alvorada": Intelectuais negros e imprensa, Pelotas (1907-1957). Dissertação (Mestrado em História) UFF, Rio de Janeiro.

SANTOS, José Antônio (2011). Prisioneiros da História. Trajetória de intelectuais na imprensa negra meridional. Tese (Doutorado em História). PPGH/PUCRS, Porto Alegre.

SANTOS, Neuza (1983). Tornar-se negro. Rio de Janeiro: Graal.

SILVA, Fernanda Oliveira da (2011). Os negros, a constituição de espaços para os seus e o entrelaçamento desses espaços: associações e identidades negras em Pelotas (1820- 1943). Dissertação (Mestrado em História). PPGH-PUCRS, Porto Alegre.

SILVA, Fernanda Oliveira da (2017). As lutas políticas nos clubes negros: culturas negras, racialização e cidadania na fronteira Brasil-Uruguai no pós-abolição (1870-1960). Tese (Doutorado em História), Programa de Pós-graduação em História, UFRGS, Porto Alegre.

SILVA, Petronilha Beatriz Gonçalves e (2005). "Aprendizagem e ensino das africanidades 50 brasileiras.”. In: MUNANGA, Kabenguele (Org.). Superando o Racismo na Escola. 2. ed. Brasília: Ministério da Educação, Secretaria de Educação Continuada, Alfabetização e Diversidade, pp. 155-172.

TORRES, Nelson Maldonado (2005). Mapping Decolonial Turn, Berkeley.

XAVIER, Regina Célia Lima (org.) (2007). História da Escravidão e da Liberdade no Brasil Meridional: guia bibliográfico. Porto Alegre: UFRGS.

ZORZI, José Augusto (2019). A construção do feriado do Dia da Consciência Negra em Porto Alegre (2001-2019): luta e política do reconhecimento. Dissertação (Mestrado em História), Programa de Pós-graduação em História, UFRGS, Porto Alegre/RS.

ZUBARAN, Maria Angélica (2008). Comemorações da liberdade: lugares de memórias negras diaspóricas. Anos 90 - Revista do PPG em História da UFRGS. V. 15, n.27, pp.161-187. Disponível em: <http://seer.ufrgs.br/anos90/article/view/6743/4045>. Acesso em: 11 maio 2011. 
ZUBARAN, Maria Angélica (2020). Médicos negros no pós-Abolição: Chagas Carvalho, Arnaldo Dutra e Diógenes Baptista (Porto Alegre, RS) In. MAMIGONIAN Beatriz Gallotti,MENDONÇA, Joseli Maria Nunes \& TEIXEIRA, Luana (Orgs.). Pós-Abolição no Sul do Brasil: associativismo e trajetórias negras. Salvador: Sagga. pp.120-142.

Artigo recebido em 26 de dezembro de 2021.

Aprovado em 25 de maio de 2021.

DOI: $10.12957 /$ intellectus.2021.56821 